\title{
Synthesis and Physicochemical Properties of Double-Chain Cationic Surfactants
}

\author{
Sinem Engin Özdil ${ }^{a}$, Halide Akbaş ${ }^{b}$, , Mesut Boz ${ }^{\text {b }}$ \\ a.Department of Chemistry, İpsala Vocational Collage, Trakya University, Edirne, TURKEY \\ $b,{ }^{*}$.Department of Chemistry, Faculty of Science, Trakya University, Edirne, TURKEY
}

* Address of corresponding Author

Prof. Dr. Halide Akbaş

Department of Chemistry, Faculty of Science

Trakya University, 22030, Edirne, TURKEY

Fax: +90 284 2351198, Tel: +90 5344110563

E-mail: hakbas34@yahoo.com 
Supporting Information B : ${ }^{1} \mathrm{H}$ NMR spectra and ${ }^{13} \mathrm{C}$ NMR of $16-2-16$

${ }^{1} \mathrm{H}$ NMR spectra and ${ }^{13} \mathrm{C}$ NMR Spectra of 10-0-10

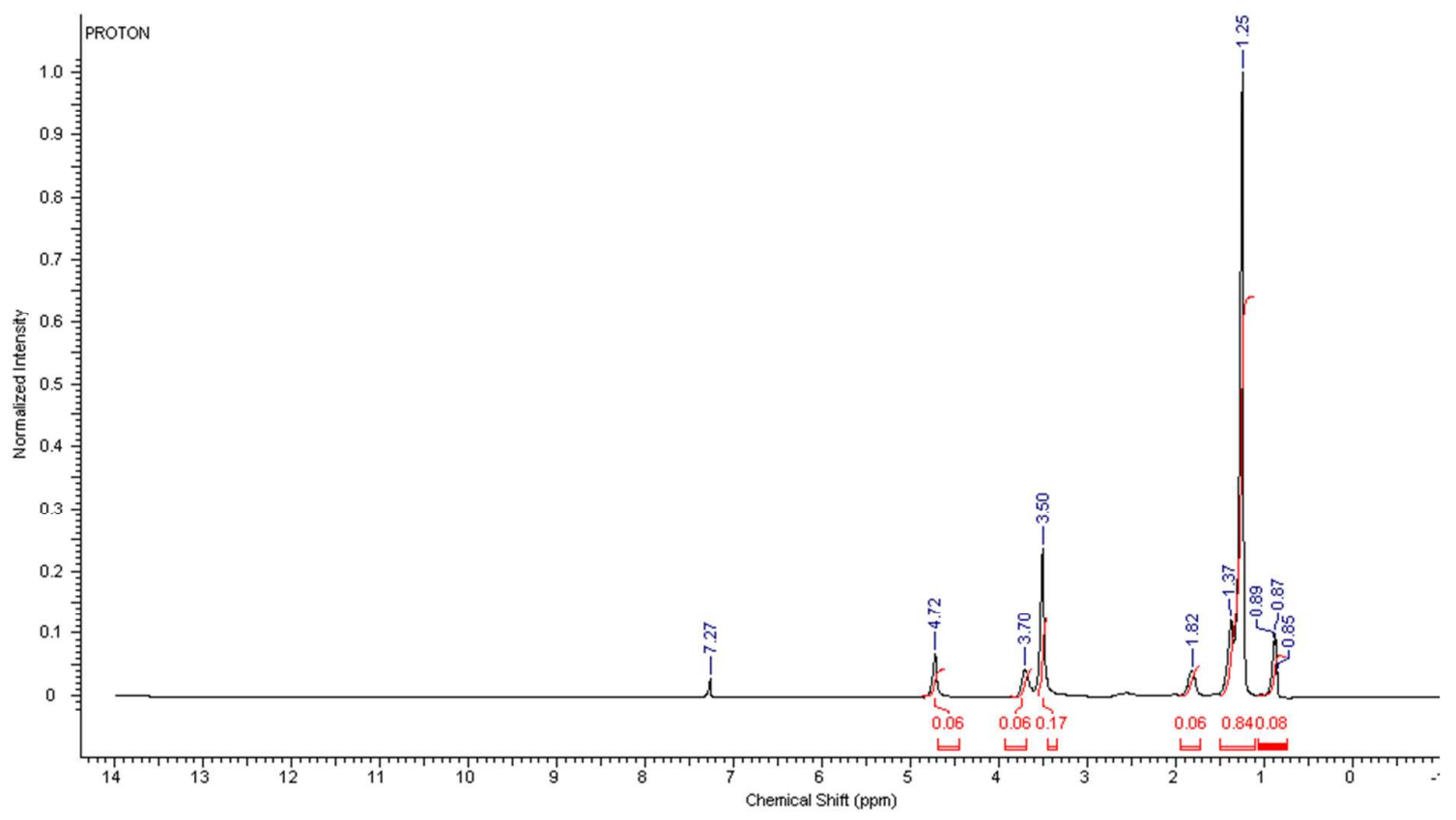

Figure S2a. ${ }^{1} \mathrm{H}$ NMR spectra of 16-2-16 


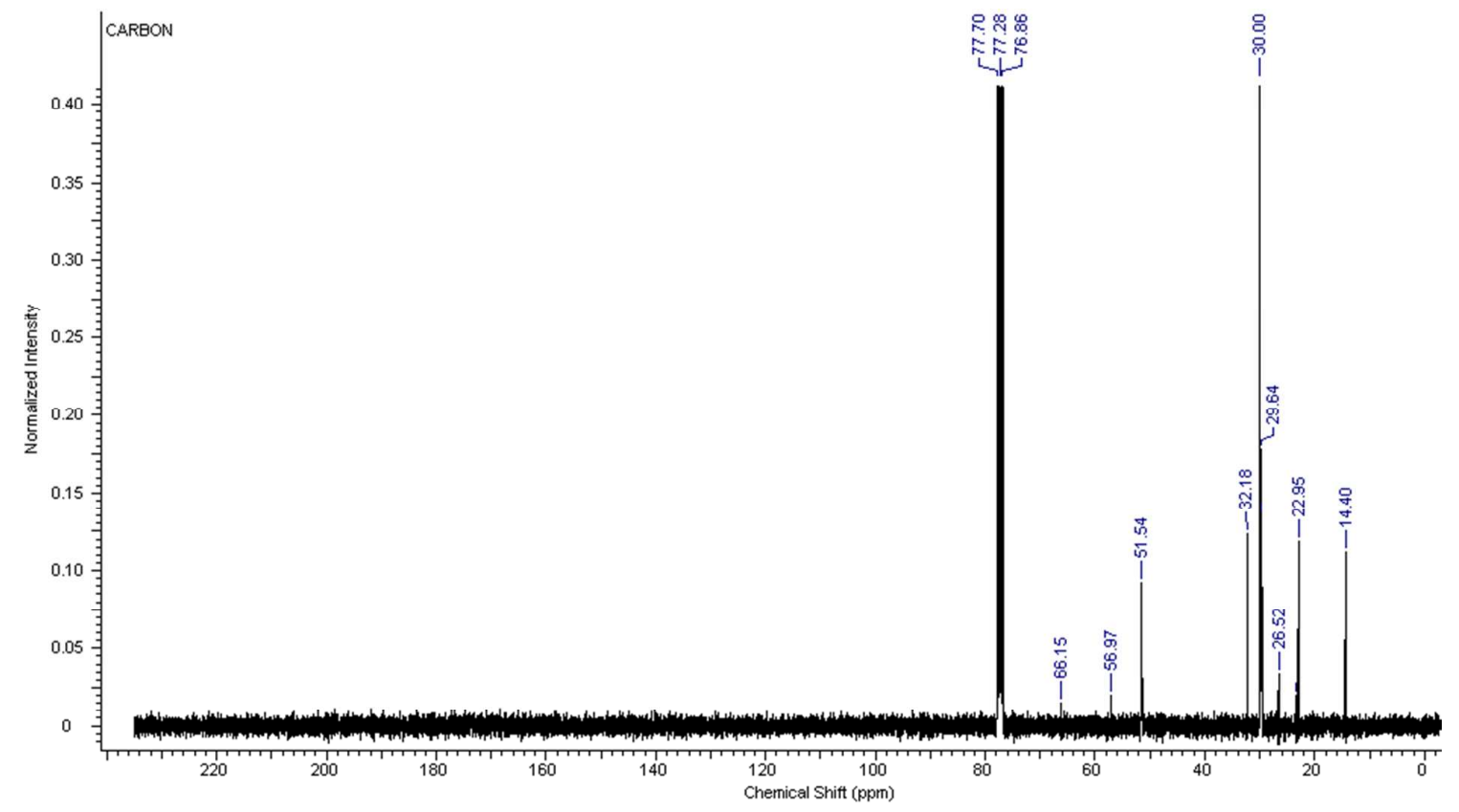

Figure S2a. ${ }^{1}$ H NMR spectra of 16-2-16 
Figure S3a. ${ }^{1} \mathrm{H}$ NMR Spectra of 10-0-10 
ERDEM.1_03May201

Archive directory: /export/home/vnur1/vnmrsys/data

Sample directory: ERDEM.1_03May2011

File: PROTON

Pu1se Sequence: s2pul

Solvent: CDC13

Temp. $20.0 \mathrm{C} / 293.1 \mathrm{~K}$

Mercury-300BB "Tahir"

Relax. delay $1.000 \mathrm{sec}$

Pulse 45.0 degrees

Acq. time $1.998 \mathrm{sec}$

wiath $4798.5 \mathrm{~Hz}$

8 repetitions

DATA PROCESSTNG

FT

Total time $0 \mathrm{~min}, 25 \mathrm{sec}$

Figure S3b. ${ }^{1}$ H NMR Spectra of 10-0-10 


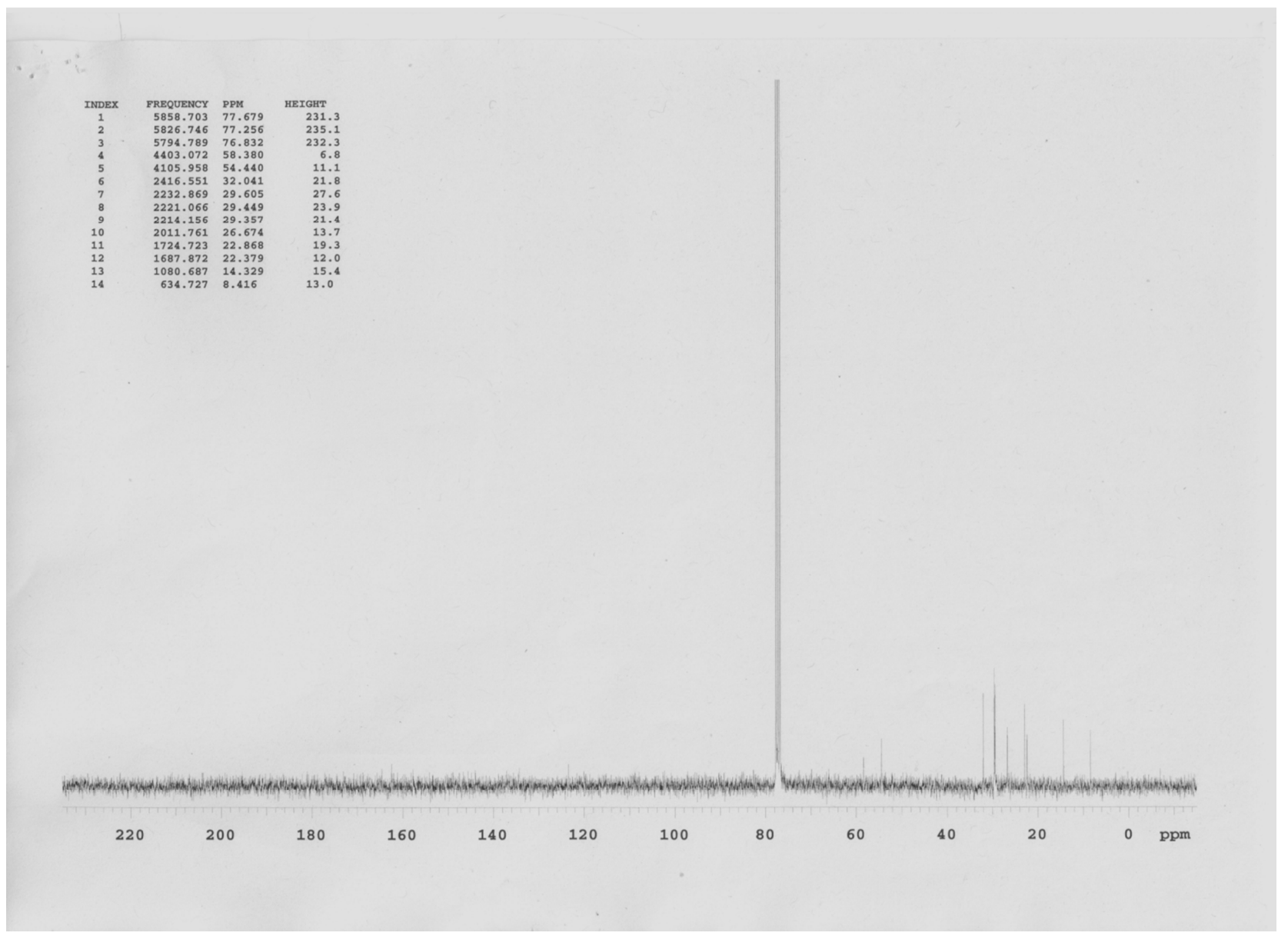

Figure S3c. ${ }^{13} \mathrm{C}$ NMR Spectra of 10-0-10 